\title{
Occurrence of Aflatoxin M1 in Milk-based Mithae samples from Pakistan
}

https://doi.org/10.1515/chem-2019-0123

received September 25, 2017; accepted january 31, 2018.

\begin{abstract}
Milk products with aflatoxin M1 (AFM1) contamination are a lethal dilemma worldwide due to their carcinogenic and mutagenic effects especiallyin developing countries. This study investigated the occurrence of AFM1 in milk-based mithae samples marketed in Lahore, Pakistan. Two hundred $(n=200)$ different types of mithae samples were analyzed for AFM1 using a HPLC florescence detector. Results showed that AFM1 was present in $76 \%$ of the analyzed samples, of which more than $80 \%$ had a much higher level of AFM1 than the European Union permissible level of i.e.0.05 $\mu \mathrm{g} / \mathrm{kg}$ in milk products. The aflatoxin M1 in all the tested samples was observed in the range of 0.004 to $1.49 \mu \mathrm{g} / \mathrm{kg}$. On average, the Gulab Jamun and Malai Laddu showed the highest level of aflatoxin M1 i.e. 1.49 and $1.17 \mu \mathrm{g} / \mathrm{kg}$, respectively. The lowest amount

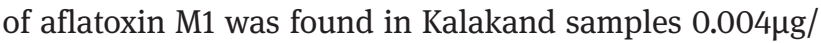
$\mathrm{kg}$. The conclusion drawn from this data revealed that almost three-fourths of the mithae samples were highly contaminated with AFM1 due to their main component, milk. The consumption of milk-based mithae is popular due to health benefits as well as being part of tradition. Instead of being nourishing and beneficial, it is been found to be hazardous to human health due to aflatoxin contamination. Continued monitoring of aflatoxin M1with strict rules and regulations is required to prevent aflatoxin accumulation in this favorite food commodity.
\end{abstract}

Keywords: Aflatoxin M 1; Mithae; HPLC; contamination; Barfi; ICA.

\footnotetext{
*Corresponding author: Mateen Abbas, Department of Toxicology, Quality Operations Laboratory, University of Veterinary and Animal Sciences, Lahore, Pakistan, E-mail: mateen.abbas@uvas.edu.pk Narjis Naz, Anam Rubab, Department of Chemistry, Lahore College for Women University, Lahore, Pakistan Kinza Kanwal, Department of Pharmacology and Toxicology, University of Veterinary and Animal Sciences, Lahore, Pakistan †“Dr. Narjis Naz was a detailed-oriented and innovative thinker devoted to logic, which served him well in both science and related areas of study. I have found him to be an enthusiastic and creative person. She was a team player able to glean optimal performance while consistently producing high quality work in a timely manner“.
}

\section{Introduction}

In Pakistani culture, milk-based mithae (sweets) is a most popular traditional sweet treat.. It is composed of various ingredients such as sugar, ghee, flavoring, food color, nuts, and especially milk. It is a highly nutritious food containing macro and micro-nutrients essential for human health. Mithae has established itself as a symbol of social event celebrations such as Eid happiness festival, Noroz, child births, weddings, and winnings etc. and also signifies encouragemtn, happiness and prosperity in Pakistan [1].The strong bond between traditions, customs, festivities and mithae has accelerated mithae's consumption of high nutritional value, but conversely, the consumption has a large quantity of aflatoxin M1 [1-2].The most important ingredient, milk, environment, processing and storage conditions have been listed to have an impact on the development of the aflatoxins in these food commodities(Mithae) [2].

Aflatoxins are the sub group of a large family known as mycotoxins generally produced by toxigenic strains of Aspergillus flavus, Aspergillus. nominus, and Aspergillus. parasiticus grow on agricultural foodstuffs [3-5]. Aflatoxin B1, aflatoxin B2, aflatoxin G1 and aflatoxin G2 are the major classes of aflatoxins while aflatoxin $\mathrm{B} 1$ is the most toxic, teratogenic and mutagenic class of aflatoxins. International Agency for Research on Cancer documented it as group I human carcinogen [6-8]. Aflatoxin M1 is a hydroxylated metabolite of AFB1 [9], that is excreted in the milk of dairy animals who have ingested contaminated food. The proportion of feed-totissue transfer for aflatoxin B1 is the maximum in milk, which is bio-transformed to aflatoxin M1 (known as milk toxin) by the hepatic microsomal mixed-function oxidase system [10-11]. It has been classified as a group 2B toxin and considered a possible hazard to humans [12]. Milk has the confirmed potential for introducing AFM1 into the human diet through its pure form and products [13-14]. Exposure of living systems to harmful levels of aflatoxin M1 results in the formation of epoxide, which reacts with proteins and DNA leading to DNA-adducts, thus causing liver cancer [15-17]. It persists to some degree in food even 
after food processing methods such as high temperatures have inactivated the fungi, due to their significant chemical stability $[5,18]$. The presence of AFM1 in milk and milk-based products have been reported from different countries as well as Pakistan [6,19-21]. Yet, only one report exists on the incidence of AFM1 in Barfi from Pakistan.

Strict regulatory limits are currently in place in most countries because of high toxicity levels and health concerns. The international regulations for the maximum limit of AFM1 in milk and dairy products range from 0 to 10 $\mu \mathrm{g} / \mathrm{kg}$. In the European Commission (EC) Directive (2006), the maximum AFM1 content in liquid milk and milk-based products intended for human intake has been set at 0.05 $\mu \mathrm{g} / \mathrm{kg}[6,7,22]$. The USA has set an upper limit of $0.5 \mu \mathrm{g} / \mathrm{kg}$, which is much higher than that of the EC [23].The Pakistan Standard and Quality Control Authority has recently set the maximum limit for aflatoxin M1 in milk at $10 \mathrm{ppb}$ [24]. No further limits have been set for AFM1 in milk products.

Several analytical methods exist for the detection of AFM1 in milk commodities with a comparable basic protocol of extraction, clean-up, separation, detection and quantification. However, at this time, immunoaffinity column (IAC) clean-up followed by RP-HPLC with a fluorescence detector has emerged as a promising technique for the reliable detection and quantification of aflatoxins in diversified foods [21,25].

The present study was intended to assess aflatoxin M1 contamination in various Mithae products collected from different markets of Lahore, Pakistan using a RP-HPLC fluorescence detector. These findings will behelpful to deliver some suggested references to correlate the contamination level with EU recommended limits, health hazards associated with this toxin as well as public awareness for mithae consumers. Moreover, this study intends to alert and involve legislative authorities to consider stricter regulations because of public health concerns.

\section{Experimental}

\subsection{Material and methods}

\subsubsection{Sampling:}

Two hundred samples of different types of freshly prepared milk-based mithae were purchased randomly from the local area/markets within Lahore, Pakistan during the period of March to July 2017. The samples contained 20 samples of each type i.e. Gulab jamun, Rasgulleh, Barfi, Ras Malai, Balushahi, Khoya, Carrot Halwa, Kalakand, Malai laddu, peda. All the samples of Mithae had the main ingredient of milk, sugar and ghee. Properly labeled samples were transported to the laboratory and were stored at $-4^{\circ} \mathrm{C}$ before the analysis of aflatoxin M1.

\subsubsection{Chemicals and Reagents:}

The standard for aflatoxin M1 in acetonitrile was purchased from Sigma Aldrich (Germany), whereas the immunoaffinity columns (IAC) Afla $\mathrm{M}^{\mathrm{TM}}$ were purchased from VICAM (Watertown, MA, USA). All other chemicals and reagents were of analytical grade. The experiments used deionized water after filtering through a 0.45 micron filter with a Waters Millipore (Milford, MA, USA) system. Solvents and water were degassed for 30 min using an ultrasonic bath. The calibration curve for AFM1 was determined using a series of calibration solutions in acetonitrile with concentrations of $0.05,0.1,0.5,1.0$, 5.0, and $10.0 \mu \mathrm{g} / \mathrm{L}$. The working standard solutions were prepared according to the Association of Official Analytical Chemists (AOAC) method [26] and stored at $20^{\circ} \mathrm{C}$ in amber glass vials until analysis. The response was linear $\left(\mathrm{R}^{2}=0.9988\right)$.

\subsubsection{Extraction procedure for Aflatoxin M1:}

Aflatoxin M1 was analyzed in milkbased mithae according to the method reported in the literature [27] with little modification. 25 grams of well-homogenized mithae samples were added and placed in a conical flask containing a mixture of acetonitrile: water $(150 \mathrm{~mL})$ and then $5 \mathrm{~g}$ of sodium chloride. The flasks were covered with aluminum foil and placed in a water bath (WTO/ PAT/E/013) and stirred for 4-5 hours at a temperature of $37^{\circ} \mathrm{C}$ and 120 oscillations. The resulting mixture was filtered by a Whatman filter paper No. 5. A portion of the above filtrate was passed through an immune affinity column. The column was then washed with water. AFM1 was eluted with methanol into a glass vial. The eluate was then evaporated until dry under $\mathrm{N}_{2}$ blanketing, and the residue was reconstituted in a mobile phase comprising of water: acetonitrile $(7: 3, v / v)$. Vortex the samples for 15 minutes, and the $1 \mathrm{~mL}$ sample was filtered by micron filter paper of 0.25 microns in the small vials and then analyzed. 


\subsubsection{HPLC conditions:}

A high performance liquid chromatography instrument model Agilent 1100 with C18 (4.6× $250 \mathrm{~mm}, 5.0 \mu \mathrm{m})$ analytical column and fluorescence detection set at FL Ex $365 \mathrm{~nm}$, Em $435 \mathrm{~nm}$ was used for to analyze aflatoxin M1. The mobile phase consisting of acetonitrile: water (3:7 v/v) was used at a flow rate of $1 \mathrm{~mL} \mathrm{~min}^{-1}$. The injection volume was $20 \mu \mathrm{L}$ for both standard solution and sample extracts.

\subsubsection{Validation and Recoveries:}

Validation parameters like linearity, Limit of detections (LOD), Limit of quantifications (LOQ), repeatability and reproducibility of Aflatoxin M1 are calculated. LOD and LOQ for AFM1 was $0.03 \mu \mathrm{g} / \mathrm{kg}$ and $0.01 \mu \mathrm{g} / \mathrm{kg}$, respectively. The recoveries were ascertained by spiking $0.1,0.2$ and $0.4 \mu \mathrm{g} / \mathrm{kg}$ of AFM1 in different types of mithae with threereplicated analyses shown in Table 1 . The fortified samples were extracted and analyzed using the same procedure. The method showed good recoveries that varied from $95 \pm$ 2.5to $78 \pm 3 \%$ [28].

\subsubsection{Statistical analysis:}

All the measurements of the milk-based mithae samples were repeated three times, and the data was statistically analyzed and presented as mean and range by using SPSS software (IBM SPSS Statistics, 20, USA). Regression analyses were applied to determine the coefficient of determination (国). Samples with a higher concentration of aflatoxin M1 than the limit of detection were considered positive, while the samples with concentrations lower than the limit of detection were considered negative.

Ethical approval: The conducted research is not related to either human or animal use.

\section{Results and Discussion}

Milk-based mithae is the most consumed food in Asian countries especially in Pakistan, owing to their specific flavor, traditional importance and main ingredient, milk [2]. Milk is a highly nutritious constituent of mithae however, it tends to have a maximum quantity of aflatoxin M1, a serious risk to consumer health and food safety $[19,29]$. The presence of aflatoxin M1 (AFM1) in milk and
Table 1: \%Recovery of Spiked Samples of Milk Based Mithae.

\begin{tabular}{|c|c|c|c|}
\hline Sample Type & $\begin{array}{l}\text { Fortified con- } \\
\text { centration of } \\
\text { AFM } 1 \mu g / K g\end{array}$ & $\begin{array}{l}\text { AFM1 recovered } \\
\mu \mathrm{g} / \mathrm{kg} \pm \mathrm{SD}\end{array}$ & $\begin{array}{l}\text { Recovery \% } \\
(\text { Mean } \pm \text { SD) } \\
\mu \mathrm{g} / \mathrm{kg}\end{array}$ \\
\hline \multirow[t]{3}{*}{ Gulab jamun } & 0.1 & $0.08 \pm 0.01$ & $80.0 \pm 10.0$ \\
\hline & 0.2 & $0.16 \pm 0.015$ & $83 \pm 5.78$ \\
\hline & 0.4 & $0.38 \pm 0.03$ & $94 \pm 3.60$ \\
\hline \multirow[t]{3}{*}{ Rasgulleh } & 0.1 & $0.09 \pm 0.08$ & $86 \pm 5.83$ \\
\hline & 0.2 & $0.18 \pm 0.05$ & $91.6 \pm 5.77$ \\
\hline & 0.4 & $0.36 \pm 0.04$ & $90.8 \pm 6.2$ \\
\hline \multirow[t]{3}{*}{ Barfi } & 0.1 & $0.09 \pm 0.08$ & $86 \pm 5.8$ \\
\hline & 0.2 & $0.17 \pm 0.01$ & $88 \pm 7.65$ \\
\hline & 0.4 & $0.36 \pm 0.024$ & $90 \pm 2.5$ \\
\hline \multirow[t]{3}{*}{ Ras Malai } & 0.1 & $0.08 \pm 0.06$ & $80 \pm 14.2$ \\
\hline & 0.2 & $0.16 \pm 0.021$ & $80 \pm 21.7$ \\
\hline & 0.4 & $0.35 \pm 0.012$ & $88.3 \pm 6.29$ \\
\hline \multirow[t]{3}{*}{ Balushahi } & 0.1 & $0.08 \pm 0.02$ & $80 \pm 14.1$ \\
\hline & 0.2 & $0.16 \pm 0.081$ & $90 \pm 7.6$ \\
\hline & 0.4 & $0.38 \pm 0.016$ & $95 \pm 2.5$ \\
\hline \multirow[t]{3}{*}{ Khoya } & 0.1 & $0.09 \pm 0.07$ & $85 \pm 5.7$ \\
\hline & 0.2 & $0.16 \pm 0.02$ & $80 \pm 5.0$ \\
\hline & 0.4 & $0.35 \pm 0.06$ & $88.3 \pm 9.5$ \\
\hline \multirow[t]{3}{*}{ Carrot Halva } & 0.1 & $0.08 \pm 0.07$ & $81 \pm 14.1$ \\
\hline & 0.2 & $0.15 \pm 0.03$ & $78.3 \pm 20.8$ \\
\hline & 0.4 & $0.35 \pm 0.03$ & $90 \pm 9.01$ \\
\hline \multirow[t]{3}{*}{ MalaiLaddu } & 0.1 & $0.09 \pm 0.06$ & $86 \pm 5.4$ \\
\hline & 0.2 & $0.16 \pm 0.02$ & $80 \pm 13.2$ \\
\hline & 0.4 & $0.38 \pm 0.03$ & $95 \pm 2.5$ \\
\hline \multirow[t]{3}{*}{ kalakand } & 0.1 & $0.08 \pm 0.07$ & $80 \pm 5.1$ \\
\hline & 0.2 & $0.17 \pm 0.03$ & $88.3 \pm 5.7$ \\
\hline & 0.4 & $0.37 \pm 0.05$ & $93.3 \pm 7.6$ \\
\hline \multirow[t]{3}{*}{ Peda } & 0.1 & $0.08 \pm 0.13$ & $86.6 \pm 3.5$ \\
\hline & 0.2 & $0.17 \pm 0.01$ & $88.3 \pm 7.6$ \\
\hline & 0.4 & $0.37 \pm 0.4$ & $93 \pm 1.4$ \\
\hline
\end{tabular}

milk-based products is well known and has become an important problem internationally [6].

In this study, the AFM1 contamination in milk-based mithae samples was determined by HPLC-FLD. Prior to this investigation, the analysis method was developed 
Table 2: Level of AFM1 in different types of Milk based Mithae.

\begin{tabular}{llll}
\hline Sample Type & $n$ & $\begin{array}{l}\text { Positive } \\
\text { sample }\end{array}$ & Range $\mu \mathrm{g} / \mathrm{kg}$ \\
\hline Gulab Jamun & 20 & $18(90 \%)$ & $1.89-2.45$ \\
Rasgulleh & 20 & $15(75 \%)$ & $0.15-0.26$ \\
Ras Malai & 20 & $20(100 \%)$ & $1.17-1.55$ \\
Carrot Halva & 20 & $14(70 \%)$ & $0.07-0.17$ \\
Peda & 20 & $19(95 \%)$ & $0.2-0.33$ \\
Malai Laddu & 20 & $17(85 \%)$ & $1.5-1.77$ \\
Khoya & 20 & $18(90 \%)$ & $0.3-0.44$ \\
Barfi & 20 & $16(80 \%)$ & $0.7-0.96$ \\
Kalakand & 20 & $8(40 \%)$ & $0.1-0.3$ \\
Balushai & 20 & $7(35 \%)$ & $0.08-0.1$ \\
\hline
\end{tabular}

and validated. Mean recoveries for AFM1 added to different types of mithae samples at levels ranging from 0.1 to $0.4 \mu \mathrm{g} / \mathrm{kg}$ were $>80 \%$. The limit of detection was 0.03 $\mu \mathrm{g} / \mathrm{kg}$ while the limit of quantification was $0.01 \mu \mathrm{g} / \mathrm{kg}$. No interferences from matrix components were observed, as standard and samples had the same AFM1 peak retention time (Figure 1 and 2). Chromatograms displayed good accuracy and reproducibility for the mithai samples.

A total of 200 samples of the different types of mithae were analyzed to evaluate the contamination level of AFM1, commonly consumed by the Pakistani population (Table 2). Results show that 152 (76\%) mithae samples were found to be contaminated with AFM1, of which $80 \%$ samples had AFM1 residue above the $0.05 \mu \mathrm{g} / \mathrm{kg}$ (EU limits for AFM1). Gulab Jamuns was highly contaminated (90\%) and had the highest mean level of 1.89-2.45 $\mu \mathrm{g} / \mathrm{kg}$ followed by malai laddu $(1.17 \pm 0.79)$. $100 \%$ contamination was revealed by the rasmali sample which had liquid milk as a major constituent. Kalakand samples (40\%) were shown to have the lowest contamination level i.e. $0.004 \pm 0.009$. The mithae samples that were prepared using milk as the main ingredient had a high level of AFM1 contamination such as Gulab Jamun, Malailaddu, Rasmalai and Peda. This demonstrated that milk was the source of contamination.

The contamination level of the different types of mithai were compared and publicized in Figure 3. The study shows that this issue needs to be examined further and with more wide-ranging data. AFM1 contamination is a worldwide problem as there is available data on the contamination of AFM1 in milk and milk-derived products [6,19-20]. Mostly cheese, yogurt, halva, milk-based drinks and milk-based infant formula were studied by different researchers and referenced in literature. The occurrence of aflatoxin M1 in dairy products (cheese, yogurt, and dairy drinks) produced in Brazil was investigated. AFM1 was detected in $84 \%$ of the analyzed cheese, $95 \%$ of the yogurt and $72 \%$ of the dairy drink samples [30]. A total

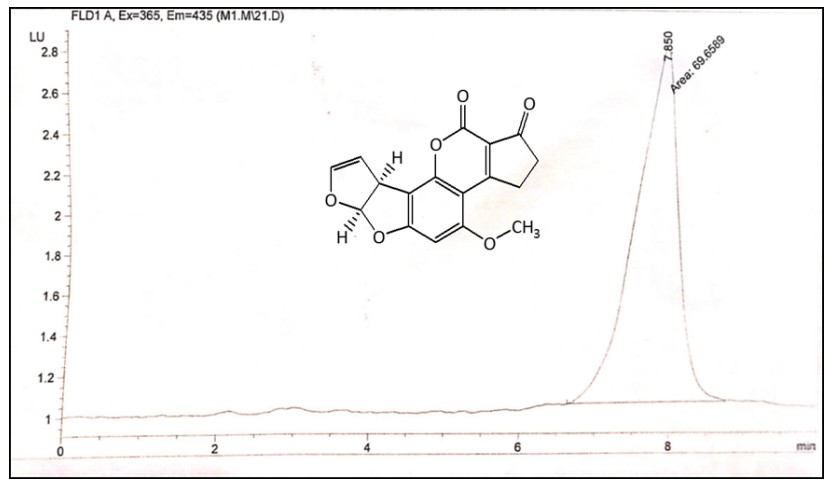

Figure 1: HPLC Chromatogram of standard solution of A.

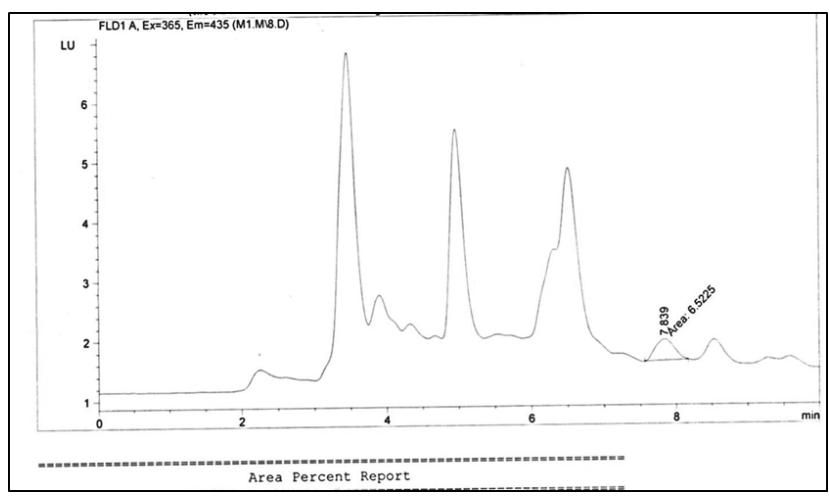

Figure 2: HPLC Chromatogram of Milk based Mithae sample.

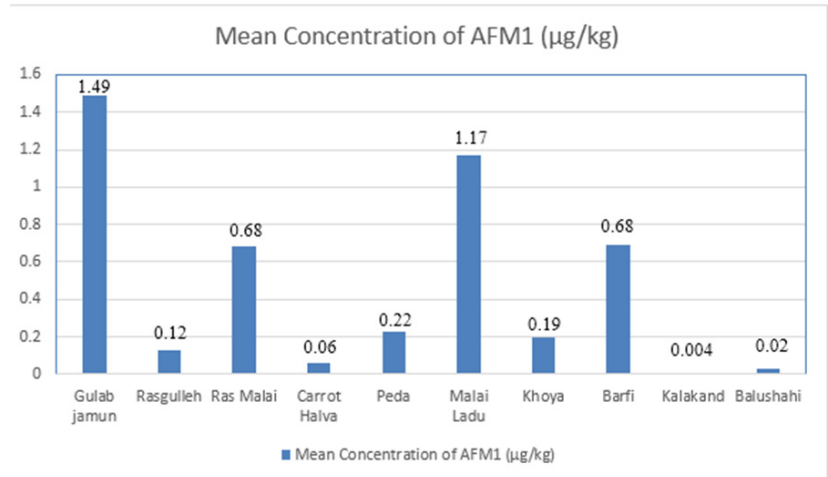

Figure 3: Comparison of AFM1 concertation in different Types of Mithae.

of 70 dairy products consisting of 24 ultra-heated treated pasteurized milk samples, 27 white cheese samples and 19 yogurt samples were analyzed for AFM1 in Ankara, Turkey. The levels of AFM1 in the samples ranged from 0.0073 to $0.1072 \mu \mathrm{g} / \mathrm{kg}$ [21]. The AFM1 was analyzed using a commercial ELISA kit for 185 samples of milk and their products from Kenya, of which 156 samples were positive with levels higher than the tolerance limit of 0.05 $\mu \mathrm{g} / \mathrm{L}[31]$. A study was conducted to screen the occurrence 
of AFM1 in 53 selected milk and dairy product samples. Of 53 samples, 19 samples were positive with AFM1. 7.5\% of the tested products had a contamination level greater than the European Commission (EC) limit in Malaysia [32]. The analysis of Halva showed that twenty samples (59\%) were found to be contaminated with AFM1, and three (9\%) samples were found to be above the recommended limit for AFM1 due to its main preparation ingredient, milk [27]. 138 sweet desserts (barfi) from Pakistan reported an AFM1 incidence rate of 97\%, and an average of AFM1 concentration of $0.48 \mathrm{mg} / \mathrm{kg}$ [2]. The former research showed the distribution/stability of AFM1 from milk to milk-based products and a possible risk for consumer health. To achieve and maintain the quality of mithae, milk samples must be evaluated routinely for AFM1. Furthermore, government agencies should monitor milk samples routinely and enforce food laws to minimize health hazards for human beings.

\section{Conclusion}

This study concluded that $76 \%$ samples of milk-based mithae marked in Lahore, Pakistan were found to be contaminated with AFM1, of which $80 \%$ of the samples were found to be above the EU permissible limits. The main ingredient, milk, was the source of the AFM1 contamination in mithae. The presence of this toxin is a serious health risk for consumers. There should be continuous monitoring of mithae for aflatoxins, and more studies should be carried out with the intent of reducing the accumulation of this toxin in milk for mithae production. Moreover, strict permissible limits should be implemented by the government to avoid aflatoxin contamination.

Conflict of interest: The authors confirm that this article content has no conflict of interest.

Acknowledgment: Authors thank the Central Laboratory of Lahore College for Women University, Lahore, and UVAS Toxicology Lab for providing Laboratory facilities.

\section{References}

[1] Naqvi I.I., Saeed Q., Farrukh M.A., Determination of trace metals ( $\mathrm{Co}, \mathrm{Cu}, \mathrm{Cd}, \mathrm{Pb}, \mathrm{Fe}, \mathrm{Ni}$ and $\mathrm{Mn}$ ) in selected sweets of different shops of Karachi city by atomic absorption spectroscopy, Pak J Biol Sci., 2004, 7, 1355-1359.
[2] Sadia A., Jabbar M.A., Deng Y., Hussain E.A., Riffat S., Naveed S., Arif M., A survey of aflatoxin M1 in milk and sweets of Punjab, Pakistan, Food Control., 2012, 26, 235-240.

[3] Luttfullah G., Hussain A., Studies on contamination level of aflatoxins in some dried fruits and nuts of Pakistan, Food Control., 2011, 22(3), 426-429.

[4] Naz N., Kashif A., Kanwal K., Khan A.M., Abbas M., Quantitative scrutinization of aflatoxins in different spices from Pakistan, Int. J. Anal. Chem., 2016, A. 4907425.

[5] Prandini A., Tansini G., Sigolo S., Filippi L., Laporta M., Piva G., On the occurrence of aflatoxin M1 in milk and dairy products, Food and Chem Toxicol., 2009, 47(5), 984-991.

[6] Iqbal S.Z., Jinap S., Pirouz A.A., Faizal A.R.A., Aflatoxin M 1 in milk and dairy products, occurrence and recent challenges: $A$ review, Trends in Food Sci \& Technol., 2015, 46(1), 110-119.

[7] Iqbal S.Z., Asi M.R., Jinap S., A survey of aflatoxin M1 contamination in milk from urban and rural farmhouses of Punjab, Pakistan, Food Addit Contam Part-B., 2014, 7(1), 17-20.

[8] Nuryono N., Agus A., Wedhastri S., Maryudani Y.B., Setyabudi F.M.C.S., Bohm J., Razzazi-Fazeli E., A limited survey of aflatoxin M1 in milk from Indonesia by ELISA. Food Control., 2009, 20(2), 721-724.

[9] Asi M.R., Iqbal S.Z., Arino A., Hussain A., Effect of seasonal variations and lactation times on aflatoxin M1 contamination in milk of different species from Punjab, Pakistan. Food Control., 2012, 25(1), 34-38

[10] Aslam N., Rodrigues I., McGill D., Warriach H., Cowling A., Haque A., Wynn P., Transfer of aflatoxins from naturally contaminated feed to milk of Nili-Ravi buffaloes fed a mycotoxin binder, Anim. Prod. Sci., 2015, doi:10. 1071/AN14909.

[11] Jalili M., Scotter M., A review of aflatoxin M1 in liquid milk, Iran J Health Saf Environ., 2015, 2(2), 283-295.

[12] Caloni F., Stammati A., Grigge G., Angelis I.D., Aflatoxin M1 absorption and cytotoxicity on human intestinal in vitro model, Toxicon., 2006, 47, 409-415.

[13] Iqbal S.Z., Asi M.R., Arino A., Aflatoxin M1 contamination in cow and buffalo milk samples from the North West Frontier Province (NWFP) and Punjab provinces of Pakistan, J. Food Addit. Contam., 2011, 282-288.

[14] Gurbay A., Aydin S., Girgin G., Engin A.B., Sahin G., Assessment of aflatoxin M1 levels in milk in Ankara, Turkey, Food Control., 2006, 17, 1-4.

[15] Cucci C., Mignani A.G., Dall'Asta C., Pela R., Dossena A., A portable fluorometer for the rapid screening of $M 1$ aflatoxin Sens, Actuators B., 2007, 126, 467-472.

[16] Afsah-Hejri L., Jinap S., Hajeb P., Radu S., Shakibazadeh S. H., A review on mycotoxins in food and feed: Malaysia case study, Compr Rev Food Sci F., 2013, 12, 629-651.

[17] Gursoy-Yuzugullu O., Yuzugullu H., Yilmaz M., Ozturk M., Aflatoxin genotoxicity is associated with a defective DNA damage response by passing p53 activation, Liver International., 2011, 31(4), 561-571.

[18] Abdallah M.I., Bazalou M.S., Al-Julaifi M.Z., Determination of aflatoxin M1 concentrations in full-fat cow's UHT milk sold for consumption in Najran-Saudi regarding its public health significance, Egypt. J. of Appl. Sci., 2012, 27(3), 40-54.

[19] Aslam N., Wynn P.C., Aflatoxin contamination of the milk supply: A Pakistan perspective, Agriculture., 2015, 5(4), 1172 1182. 
[20] Ketney O., Santini A., Oancea S., Recent aflatoxin survey data in milk and milk products: A review, Int J Dairy Technol., 2017.

[21] Sarica D.Y., Has O., Taşdelen S., Ezer U., Occurrence of aflatoxin M1 in milk, white cheese and yoghurt from Ankara, Turkey markets, Biol Chem Research., 2015, 36-49.

[22] European Commission, Commission Regulation (EC) No. 401/2006 of 23 February 2006 laying down the methods of sampling and analysis for the official control of the levels of mycotoxins in foodstuffs. Off J Eur Union. L70:12-34, 2006.

[23] WHO. Toxicological Evaluation of Certain Food Additives with a Review of General Principle and of Specifications; World Health Organization: Geneva, Switzerland, 1974.

[24] Ashiq S., Natural occurrence of mycotoxins in food and feed: Pakistan perspective. Compr. Rev. Food Sci. Food Saf., 2015, 14, 159-175.

[25] Mushtaq M., Sultana B., Anwar F., Khan M.Z., Ashrafuzzaman M., Occurrence of aflatoxins in selected processed foods from Pakistan, Int. J. Mol. Sci., 2012, 13(7), 8324-8337.

[26] IARC, IARC monographs on the evaluation of carcinogenic risks to humans. In Traditional herbal medicines, some mycotoxins, naphthalene and styrene (Vol.82). Lyon: IARC Press., 2002, 1-556.

[27] Iqbal S.Z., Asi M.R., Jinap S., Natural occurrence of aflatoxin B1 and aflatoxin M1 in "halva" and its ingredients, Food Control., 2013, 34, 404-407.

[28] Sizoo E.A., Egmond V., Analysis of duplicate 24-hour diet samples for aflatoxin B1, aflatoxin M1 and ochratoxin A, Food Addit. Contam., 2005, 22, 163-172.

[29] Bellio A., Bianchi D.M., Gramaglia M., Loria A., Nucera D., Gallina S., Decastelli L., Aflatoxin M1 in Cow's Milk: Method Validation for Milk Sampled in Northern Italy, Toxins., 2016, 8(3), 57.

[30] Iha M.H., Barbosa C.B., Okada I.A., Trucksess M.W., Occurrence of aflatoxin M 1 in dairy products in Brazil, Food Control., 2011, 22(12), 1971-1974.

[31] Langat G., Tetsuhiro M., Gonoi T., Matiru V., Bii C., Aflatoxin M1 Contamination of milk and its products in Bomet County, Kenya, Adv Microbiol ., 2016, 6(07), 528.

[32] Nadira A.F., Rosita J., Norhaizan M.E., Redzwan S.M., Screening of aflatoxin M1 occurrence in selected milk and dairy products in Terengganu, Malaysia, Food Control., 2017, 73, 209-214. 